\title{
Comparison of 2-D Magnetic Designs of Selected Coil Configurations for the Next European Dipole (NED)
}

\author{
F. Toral, A. Devred, H. Felice, P. Fessia, P. Loveridge, F. Regis, J. Rochford, S. Sanz, N. Schwerg, \\ $\mathrm{P}$. Vedrine, and C. Vollinger
}

\begin{abstract}
The Next European Dipole (NED) activity is developing a high-performance $\mathrm{Nb}_{3} \mathrm{Sn}$ wire (aiming at a non-copper critical current density of $1500 \mathrm{~A} / \mathrm{mm}^{2}$ at $4.2 \mathrm{~K}$ and $15 \mathrm{~T}$ ), within the framework of the Coordinated Accelerator Research in Europe (CARE) project. This activity is expected to lead to the fabrication of a large aperture, high field dipole magnet. In preparation for this phase, a Working Group on Magnet Design and Optimization (MDO) has been established to propose an optimal design. Other parallel Work Packages are concentrating on relevant topics, such as quench propagation simulation, innovative insulation techniques, and heat transfer measurements. In a first stage, the MDO Working Group has selected a number of coil configurations to be studied, together with salient parameters and features to be considered during the evaluation: the field quality, the superconductor efficiency, the conductor peak field, the stored magnetic energy, the Lorentz Forces and the fabrication difficulties. 2-D magnetic calculations have been performed, and the results of this comparison between the different topologies are presented in this paper. The 2-D mechanical computations are ongoing and the final stage will be 3-D magnetic and mechanical studies.
\end{abstract}

Index Terms-Accelerator magnets, electromagnetic analysis, electromagnetic fields, superconducting magnets.

\section{INTRODUCTION}

A Working Group on Magnet Design and Optimization has been established within the NED collaboration [1], with participants from four Institutes: CEA/Saclay, CERN, CIEMAT and RAL. This Working Group has been charged with addressing the following questions:

1) How far can we push the conventional, $\cos -\theta$ layer, design in the aperture $v s$. central field parameter space (especially, when relying on strain-sensitive conductors)?

2) What are the most efficient alternatives in terms of performances, manufacturability and costs?

Manuscript received August 29, 2006. This work was supported in part by the European Community-Research Infrastructure Activity under the FP6 "Structuring the European Research Area" program (CARE contract RII3-CT-2003506395).

F. Toral and S. Sanz are with CIEMAT, Madrid, 28040 Spain (e-mail: fernando.toral@ciemat.es; s.sanz@ciemat.es).

A. Devred is with the CEA, Saclay, France. He is also with the CERN, Geneva, Switzerland.

H. Felice and P. Vedrine are with CEA, Saclay, France (e-mail: arnaud.devred@cern.ch; hfelice@dapnia.cea.fr; vedrine@dapnia.cea.fr).

P. Fessia, F. Regis, N. Schwerg, and C. Vollinger are with CERN, Geneva, Switzerland (e-mail: arnaud.devred@cern.ch; paolo.fessia@cern.ch; federico. regis@ cern.ch; nikolai.schwerg@cern.ch; christine.vollinger@cern.ch).

P. Loveridge and J. Rochford are with RAL, Abingdon, England (e-mail: P.Loveridge@rl.ac.uk; J.H.Rochford@rl.ac.uk).

Digital Object Identifier 10.1109/TASC.2007.898418
A number of configurations have been selected (see Fig. 1): slotted $\cos -\theta$, slotted motor-type, toroidal motor-type, and common coil (studied at CIEMAT); ellipse-type (studied at CEA); double helix dipole (studied at RAL, not included in this paper as it is a pure 3-D problem); and, finally, the conventional layered $\cos -\theta$ (studied at CERN and RAL).

Table I shows the common starting parameters for all the coil configurations. The strand is the one defined in the NED cable specifications, whose diameter is $1.25 \mathrm{~mm}$. A wide cable is useful for a high field magnet, as the self-inductance is lower, and the engineering current density increases. The upper limit is 40 strands in each cable, given by the available cabling machines in Europe. The cable dimensions are derived from empirical formulae according to previous experiences [2]. All the designs use rectangular Rutherford-type cable, except the layered $\cos -\theta$, which uses a slightly keystoned one.

\section{2-D Magnetic CAlculations for Selected Designs}

\section{A. Layered Cos - $\theta$ Design}

The conventional layered $\cos -\theta$ configuration has been optimized at CERN [3]. Table II reports outstanding figures of merit of the $88 \mathrm{~mm}$ aperture dipole with round iron yoke. Special care has been taken to place the conductors in the radial direction to ease winding and mechanical support. On the other hand, a previous study [4] concluded that stresses on the coil mid-plane were above $150 \mathrm{MPa}$ for the 130 and $160 \mathrm{~mm}$ aperture dipoles, which is excessive.

As part of the optimization, an elliptical iron yoke is proposed to decrease the large variation of $b_{3}$ along the load line. The choice of an elliptical iron has one slight drawback compared to a round iron: to maintain the same bore field, it requires a few percent increase in current. In addition, ferromagnetic shims have been introduced in the coil cross-section to compensate the effect of the persistent magnetization currents. Meanwhile, the harmonic optimization has also been done with Opera2D at RAL, using a different optimization algorithm. Results are in good agreement with those obtained using Roxie at CERN.

In short, the advantages of this topology are the low peak-tobore-field ratio, the good superconductor efficiency, the good magnetic field quality, the low stored magnetic energy and the small overall magnet size. The only disadvantage is the high coil mid-plane stress. One must notice that the stresses have been computed as the sum of the block forces averaged over the corresponding cable dimension. Therefore, the actual local pressure can be higher, typically up to $20 \%$. 

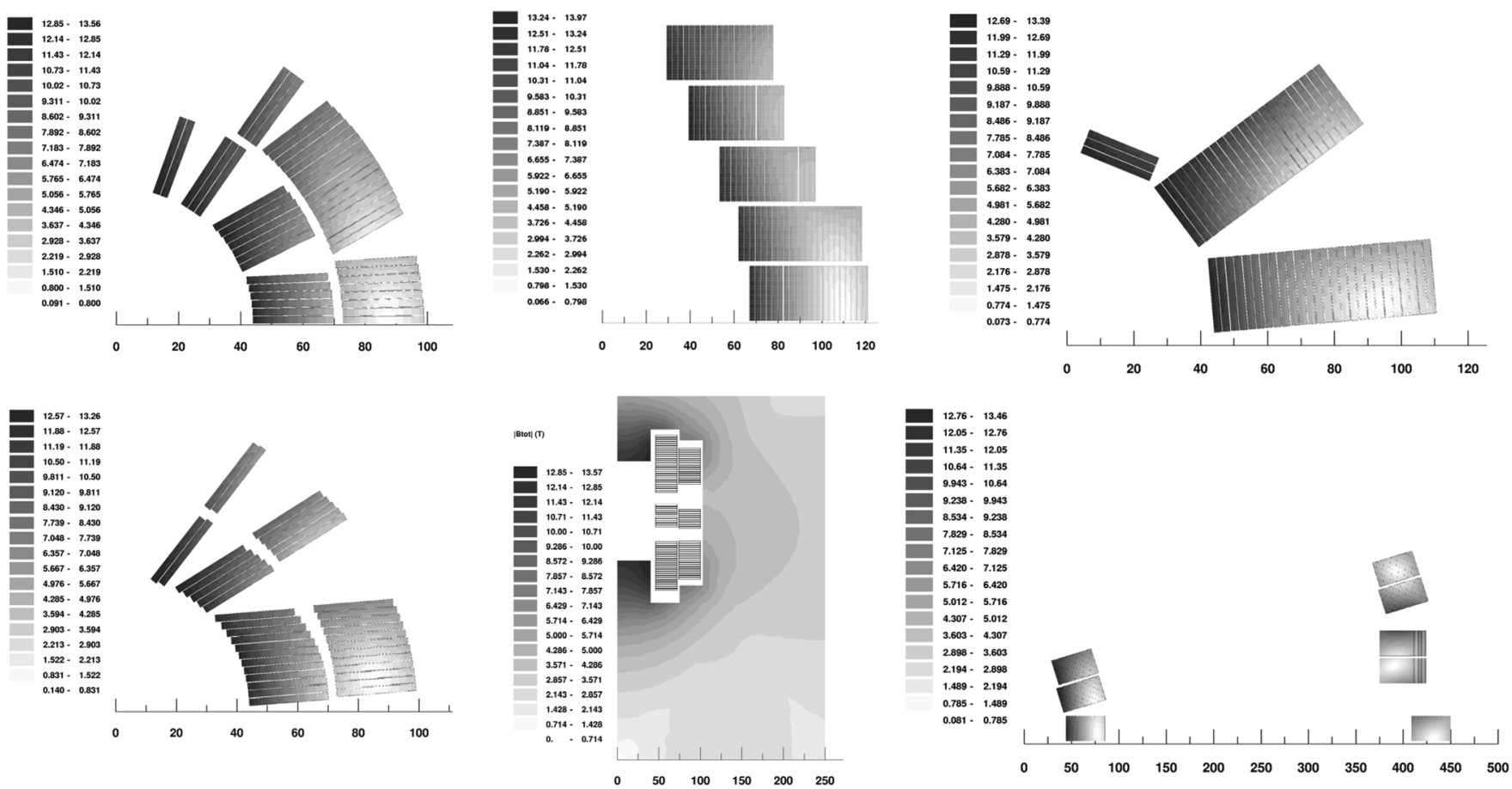

Fig. 1. Magnetic field (T) map in the studied coil configurations. From left to right, up to down: Layered $\cos -\theta$, ellipse-type, slotted motor-type, slotted cos $-\theta$, common coil and toroidal motor-type design.

TABLE I

COMMON STARTING PARAMETERS FOR THE MAGNET OPTIMIZATION

\begin{tabular}{lll}
\hline Peak field on conductor & 15 & $\mathrm{~T}$ \\
Aperture & $88-130-160$ & $\mathrm{~mm}$ \\
Reference radius & $29-43-53$ & $\mathrm{~mm}$ \\
Superconductor $J_{c}$ & 3000 & $\mathrm{~A} / \mathrm{mm}^{2} @ 4.2 \mathrm{~K}$ and $12 \mathrm{~T}$ \\
& 1500 & $\mathrm{~A} / \mathrm{mm}^{2} @ 4.2 \mathrm{~K}$ and $15 \mathrm{~T}$ \\
Cu to non-Cu ratio & 1.25 & \\
Operating margin & $\geq 10$ & $\%$ \\
Filling factor of cable & 87 & $\%$ \\
Insulation thickness & 0.2 & $\mathrm{~mm}$ per conductor face \\
Cabling degradation & 10 & $\%$ \\
X-section multipoles & $\mathrm{A} \mathrm{few} 10^{-4}$ & $\mathrm{units}$ at reference radius \\
Overall coil length & 1.3 & $\mathrm{~m}$ \\
Peak stress & 150 & $\mathrm{MPa}$ \\
Max coil deformation & $<0.05$ & $\mathrm{~mm}$ (due to Lorentz forces) \\
Peak temperature & 300 & $\mathrm{~K}$ (quench) \\
Peak voltage to ground & 1000 & $\mathrm{~V}$ (quench) \\
Peak inter-turn voltage & 100 & $\mathrm{~V}$ (quench) \\
\hline \hline
\end{tabular}

\section{B. Ellipse-Type Design}

It is well-known that an elliptical coil with a uniform current density creates a uniform dipole field in a round aperture. An ellipse-type dipole has been designed at CEA/Saclay (see Fig. 1) [5]. Tables II, III, and IV show the salient results for the 88,130 and $160 \mathrm{~mm}$ apertures, respectively, and a comparison with other arrangements. The peak-to-bore-field is low and the field homogeneity is fine, but the stored magnetic energy and, therefore, the self-inductance per unit length, are greater than $\cos -\theta$ ones, because the upper layers conductors have a poor efficiency. The horizontal component of the Lorentz forces is huge and, besides, an internal support is necessary to prevent the coils from bending inwardly, which decreases the useful aperture for a given inner coil radius. Some further investigations are needed to check the feasibility of the non-planar coil ends (both mechanical 3-D computations and winding technique).

\section{Slotted Motor-Type Design}

The conductors are now placed in slots cut out in stainless steel collars, surrounded by a round iron yoke. It resembles the winding of a conventional electrical machine. From the point of view of fabrication and mechanical analysis, the coil end design is challenging, although some small NbTi models have been made some time ago at CEA/Saclay [6]. The cable bending radius can be small, and some bending is forced over the cable narrow face. However, it is a very efficient magnet, similar to the layered $\cos -\theta$ one, but the mid-plane stresses are lower, as the collar noses help to withstand the Lorentz forces of the upper blocks.

\section{Slotted Cos - $\theta$ Design}

This design is a particular case of the conventional $\cos -\theta$ design, but the inner and outer layer spacers have the same angular positions. Therefore, both spacers can be clamped together to the collars, or even coil winding can be done directly onto the collars, as for the slotted motor-type design. The cable is rectangular, to better fit both layers, but a keystoned cable would enable a better placement of the turns in the radial direction.

In any case, it seems a simple way to match the nice layered $\cos -\theta$ performance with affordable stresses on mid-plane cables. It is worth studying this design from the mechanical point of view, and to analyze the winding techniques as well.

\section{E. Common Coil Design}

An inherent problem to the common coil configuration is that some of the most effective ampere-turns-those close to the 
TABLE II

COMPARISON OF $88 \mathrm{~mm}$ APERTURE DESIGNS

\begin{tabular}{|c|c|c|c|c|c|c|c|}
\hline Magnet type & $\begin{array}{l}\text { Layered } \\
\cos -\theta\end{array}$ & Ellipse & $\begin{array}{l}\text { Slotted } \\
\text { motor }\end{array}$ & $\begin{array}{c}\text { Slotted } \\
\cos -\theta\end{array}$ & $\begin{array}{c}\text { Common } \\
\text { coil }\end{array}$ & $\begin{array}{c}\text { Toroidal } \\
\text { motor-type }\end{array}$ & Units \\
\hline Area of bare conductors/aperture & 10647 & 16761 & 10190 & 8596 & 11762 & 31668 & $\mathrm{~mm}^{2}$ \\
\hline Area of insulated conductors/aperture & 12711 & 20165 & 12283 & 10333 & 14140 & 38069 & $\mathrm{~mm}^{2}$ \\
\hline Number of strands per aperture & 7200 & 11856 & 7208 & 6080 & 8320 & 22400 & \\
\hline Outer iron yoke radius & 475 & 500 & 450 & 450 & $500 / 250$ & 450 & $\mathrm{~mm}$ \\
\hline Current & 25939 & 20243 & 23550 & 28950 & 27300 & 26700 & A \\
\hline Margin on load line & 9.44 & 10.00 & 9.98 & 10.06 & 10.07 & 9.99 & $\%$ \\
\hline Bore field & 13.05 & 13.54 & 12.93 & 12.74 & 12.60 & 12.71 & $\mathrm{~T}$ \\
\hline Peak field & 13.46 & 13.97 & 13.39 & 13.27 & 13.41 & 13.47 & $\mathrm{~T}$ \\
\hline Peak field /bore field & 1.031 & 1.032 & 1.036 & 1.041 & 1.065 & 1.060 & \\
\hline Peak field for $0 \%$ on load line & 15.01 & 15.49 & 14.88 & 14.75 & 14.92 & 14.96 & $\mathrm{~T}$ \\
\hline \multicolumn{8}{|l|}{ Magnetic field quality } \\
\hline$b_{3}$ & 0.004 & 0.136 & -0.018 & -0.099 & 0.020 & -1.931 & $10^{-4}$ units \\
\hline$b_{5}$ & -0.022 & 0.2635 & -0.012 & -0.009 & -0.181 & -0.045 & $10^{-4}$ units \\
\hline$b_{7}$ & 0.024 & 0.661 & -0.007 & -0.378 & 8.895 & 0.072 & $10^{-4}$ units \\
\hline$b_{9}--a_{2}($ common coil $)$ & 0.871 & 0.247 & -3.857 & -7.572 & -0.448 & -3.785 & $10^{-4}$ units \\
\hline$b_{11}--a_{4}($ common coil $)$ & 2.354 & -0.007 & -3.001 & -0.499 & 2.714 & -1.694 & $10^{-4}$ units \\
\hline Engineering current density & 371 & 313 & 406 & 426 & 402 & 393 & $\mathrm{~A} / \mathrm{mm}^{2}$ \\
\hline Self inductance /aperture /unit length & 4.373 & 10.71 & 5.869 & 3.112 & 5.662 & 8.380 & $\mathrm{mH} / \mathrm{m}$ \\
\hline Stored energy /aperture / unit length & 1.471 & 2.19 & 1.628 & 1.304 & 2.111 & 2.987 & $\mathrm{MJ} / \mathrm{m}$ \\
\hline \multicolumn{8}{|l|}{ Stray magnetic field } \\
\hline - at $50 \mathrm{~mm}$ of the outer iron radius & 0.03 & 0.06 & 0.096 & 0.034 & 0.908 & 1.781 & $\mathrm{~T}$ \\
\hline $\begin{array}{l}\text { - at } 1 \mathrm{~m} \text { away from the magnet center } \\
\text { Lorentz forces }\end{array}$ & 0.006 & 0.015 & 0.018 & 0.006 & 0.072 & 0.133 & $\mathrm{~T}$ \\
\hline - Fx per side of aperture & 13.4 & 19.0 & 13.9 & 12.1 & 13.1 & 11.2 & $\mathrm{MN} / \mathrm{m}$ \\
\hline - Fy per quadrant & -3.2 & -3.5 & -3.1 & -2.8 & -0.2 & -3.0 & $\mathrm{MN} / \mathrm{m}$ \\
\hline $\begin{array}{l}\text { - Maximum accumulated membrane stress } \\
\text { perpendicular to the broad side of the cable }\end{array}$ & 125 & 107 & 118 & 40 & 72 & 89 & $\mathrm{MPa}$ \\
\hline $\begin{array}{l}\text { - Maximum accumulated membrane stress parallel } \\
\text { to the broad side of the cable }\end{array}$ & 102 & 65 & 126 & 112 & 110 & 115 & $\mathrm{MPa}$ \\
\hline
\end{tabular}

TABLE III

COMPARISON OF $130 \mathrm{~mm}$ APERTURE DESIGNS

\begin{tabular}{|c|c|c|c|c|c|c|}
\hline Magnet type & Ellipse & Slotted motor & Slotted $\cos -\theta$ & Common coil & $\begin{array}{c}\text { Toroidal } \\
\text { motor-type }\end{array}$ & Units \\
\hline Area of bare conductors/aperture & 20629 & 12441 & 12215 & 14703 & 40716 & $\mathrm{~mm}^{2}$ \\
\hline Area of insulated conductors/aperture & 24818 & 14956 & 14684 & 17675 & 48946 & $\mathrm{~mm}^{2}$ \\
\hline Number of strands per aperture & 14592 & 8800 & 8640 & 10400 & 28800 & \\
\hline Outer iron yoke radius & 680 & 450 & 450 & $650 / 300$ & 450 & $\mathrm{~mm}$ \\
\hline Current & 19983 & 27450 & 28200 & 27200 & 26400 & A \\
\hline Margin on load line & 10.10 & 9.97 & 10.21 & 10.14 & 10.11 & $\%$ \\
\hline Bore field & 13.32 & 12.62 & 12.80 & 11.73 & 12.68 & $\mathrm{~T}$ \\
\hline Peak field & 13.98 & 13.42 & 13.31 & 13.41 & 13.49 & $\mathrm{~T}$ \\
\hline Peak field /bore field & 1.049 & 1.063 & 1.040 & 1.14 & 1.064 & \\
\hline Peak field for $0 \%$ on load line & 15.52 & 14.91 & 14.82 & 14.92 & 15.01 & $\mathrm{~T}$ \\
\hline \multicolumn{7}{|l|}{ Magnetic field quality } \\
\hline$b_{3}$ & 0.004 & 0.024 & -0.013 & -0.033 & 1.659 & $10^{-4}$ units \\
\hline$b_{5}$ & 0.004 & -0.005 & -0.006 & -0.679 & -0.762 & $10^{-4}$ units \\
\hline$b_{7}$ & -0.001 & -0.005 & -0.003 & 16.772 & 7.031 & $10^{-4}$ units \\
\hline$b_{9}--a_{2}($ common coil $)$ & -0.050 & -3.388 & -0.004 & 0.078 & -4.241 & $10^{-4}$ units \\
\hline$b_{11}-a_{4}($ common coil $)$ & -0.247 & -0.198 & -4.183 & -0.012 & -3.006 & $10^{-4}$ units \\
\hline Engineering current density & 309 & 404 & 415 & 400 & 388 & $\mathrm{~A} / \mathrm{mm}^{2}$ \\
\hline Self inductance /aperture /unit length & 16.92 & 6.921 & 6.021 & 9.521 & 14.456 & $\mathrm{mH} / \mathrm{m}$ \\
\hline Stored energy /aperture / unit length & 3.38 & 2.607 & 2.394 & 3.522 & 5.036 & $\mathrm{MJ} / \mathrm{m}$ \\
\hline \multicolumn{7}{|l|}{ Stray magnetic field } \\
\hline - at $50 \mathrm{~mm}$ of the outer iron radius & 0.018 & 0.285 & 0.227 & 1.206 & 2.500 & $\mathrm{~T}$ \\
\hline - at $1 \mathrm{~m}$ away from the magnet center & 0.008 & 0.063 & 0.049 & 0.137 & 0.092 & $\mathrm{~T}$ \\
\hline \multicolumn{7}{|l|}{ Lorentz forces } \\
\hline - Fx per side of aperture & 23.2 & 16.0 & 17.1 & 14.7 & 12.0 & $\mathrm{MN} / \mathrm{m}$ \\
\hline - Fy per quadrant & -4.3 & -4.1 & -4.1 & 0.2 & -3.8 & $\mathrm{MN} / \mathrm{m}$ \\
\hline $\begin{array}{l}\text { - Maximum accumulated membrane stress } \\
\text { perpendicular to the broad side of the cable }\end{array}$ & 115 & 111 & 60 & 86 & 103 & $\mathrm{MPa}$ \\
\hline $\begin{array}{l}\text { - Maximum accumulated membrane stress parallel } \\
\text { to the broad side of the cable }\end{array}$ & 76 & 144 & 104 & 112 & 125 & $\mathrm{MPa}$ \\
\hline
\end{tabular}

beam tube-must be replaced by spacers to enhance bore field quality. The coil geometry is a hybrid between two theoretical current distributions which provide a uniform field: an infinitely long current sheet and a cosine-type winding. The $b_{7}$ multipole 
TABLE IV

COMPARISON OF $160 \mathrm{~mm}$ APERTURE DESIGNS

\begin{tabular}{|c|c|c|c|c|c|c|}
\hline Magnet type & Ellipse & Slotted motor & Slotted $\cos -\theta$ & Common coil & $\begin{array}{c}\text { Toroidal } \\
\text { motor-type }\end{array}$ & Units \\
\hline Area of bare conductors/aperture & 27291 & 15155 & 14477 & 15269 & 50669 & $\mathrm{~mm}^{2}$ \\
\hline Area of insulated conductors/aperture & 32833 & 18219 & 17403 & 18355 & 60910 & $\mathrm{~mm}^{2}$ \\
\hline Number of strands per aperture & 19304 & 10720 & 10240 & 10800 & 35840 & \\
\hline Outer iron yoke radius & 820 & 500 & 500 & $700 / 350$ & 500 & $\mathrm{~mm}$ \\
\hline Current & 18281 & 26900 & 28000 & 27600 & 26200 & A \\
\hline Margin on load line & 10.80 & 10.22 & 10.04 & 10.03 & 10.01 & $\%$ \\
\hline Bore field & 13.37 & 12.87 & 12.78 & 11.43 & 12.42 & $\mathrm{~T}$ \\
\hline Peak field & 14.03 & 13.46 & 13.36 & 13.40 & 13.53 & $\mathrm{~T}$ \\
\hline Peak field /bore field & 1.049 & 1.046 & 1.045 & 1.171 & 1.089 & \\
\hline Peak field for $0 \%$ on load line & 15.69 & 14.96 & 14.85 & 14.89 & 15.03 & $\mathrm{~T}$ \\
\hline \multicolumn{7}{|l|}{ Magnetic field quality } \\
\hline$b_{3}$ & 0.09 & 0.057 & 0.005 & 0.043 & -0.439 & $10^{-4}$ units \\
\hline$b_{5}$ & -0.05 & -0.040 & 0.009 & -1.729 & 2.115 & $10^{-4}$ units \\
\hline$b_{7}$ & 0.008 & -0.029 & -0.001 & 8.791 & 4.746 & $10^{-4}$ units \\
\hline$b_{9}--a_{2}($ common coil $)$ & -0.003 & -2.128 & -1.659 & -0.048 & -7.157 & $10^{-4}$ units \\
\hline$b_{11}--a_{4}($ common coil $)$ & 0.0163 & -1.633 & -3.506 & -0.016 & -4.659 & $10^{-4}$ units \\
\hline Engineering current density & 283 & 396 & 412 & 406 & 385 & $\mathrm{~A} / \mathrm{mm}^{2}$ \\
\hline Self inductance /aperture /unit length & 30.16 & 10.199 & 8.588 & 10.828 & 22.636 & $\mathrm{mH} / \mathrm{m}$ \\
\hline Stored energy /aperture / unit length & 5 & 3.690 & 3.367 & 4.124 & 7.768 & $\mathrm{MJ} / \mathrm{m}$ \\
\hline \multicolumn{7}{|l|}{ Stray magnetic field } \\
\hline - at $50 \mathrm{~mm}$ of the outer iron radius & 0.022 & 0.338 & 0.382 & 1.119 & 3.400 & $\mathrm{~T}$ \\
\hline - at $1 \mathrm{~m}$ away from the magnet center & 0.015 & 0.092 & 0.088 & 0.161 & 0.200 & $\mathrm{~T}$ \\
\hline \multicolumn{7}{|l|}{ Lorentz forces } \\
\hline - Fx per side of aperture & 28.7 & 19.6 & 19.7 & 15.1 & 14.3 & $\mathrm{MN} / \mathrm{m}$ \\
\hline - Fy per quadrant & -5.6 & -5.3 & -5.0 & 0.4 & -4.2 & $\mathrm{MN} / \mathrm{m}$ \\
\hline $\begin{array}{l}\text { - Maximum accumulated membrane stress } \\
\text { perpendicular to the broad side of the cable }\end{array}$ & 124 & 109 & 71 & 104 & 121 & MPa \\
\hline $\begin{array}{l}\text { - Maximum accumulated membrane stress parallel } \\
\text { to the broad side of the cable }\end{array}$ & 85 & 150 & 102 & 116 & 125 & MPa \\
\hline
\end{tabular}

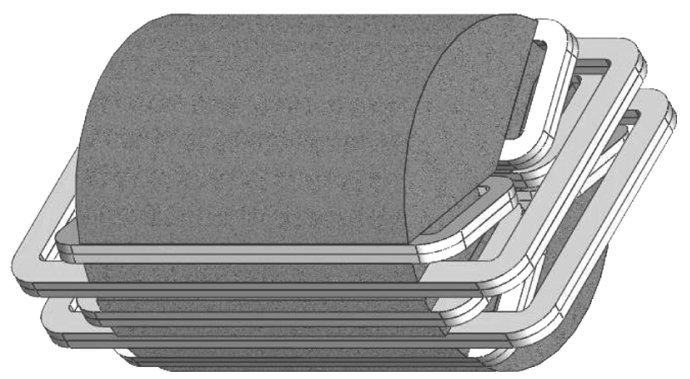

Fig. 2. Toroidal motor-type assembly with iron yoke split as a number of solid blocks. Additional anti-dipole coils are longer than dipole ones.

is not so low, as we have limited the number of spacers for the sake of simplicity and ease of fabrication. The stored magnetic energy is high, and the iron size is large. Obviously, the main advantage of this magnet is that coil winding is straightforward.

Another specific feature of this design is the two-in-one iron yoke. The distance between both apertures ranges from 600 to $700 \mathrm{~mm}$ (increasing with the aperture diameter) to weaken the cross-talk. This is also the reason for the coil up-down asymmetry. Furthermore, the even multipoles $\left(a_{2}, a_{4} \ldots\right)$ arise from the cross-talk. The peak-to-bore-field ratio is poor compared to other designs, and it would be even worse without the vertical iron poles (see Fig. 1). These poles make the assembly more difficult, but the aforementioned ratio would be about $5 \%$ higher without them [7], because the field between the left and right coil blocks is even higher than in the aperture itself, as the closest conductors to aperture have been replaced by spacers. The iron poles are deeply saturated, but they are still able to change the field lines direction.

\section{F. Toroidal Motor-Type Design}

This magnet design resembles an iron-cored toroid. In a preliminary design [7], the large additional anti-dipole coils were not present (see Fig. 2). The main advantages were the simplicity of the coil geometry and the low mid-plane coil stress. The most outstanding drawbacks were the strong fringe fields and the high number of turns, due to the anti-dipole field created by the outermost coil blocks. Therefore, additional coil blocks has been included at the outer radius, but with opposite current polarity with respect to the adjacent coil blocks. It addresses both issues: the overall number of turns is now half than before, as it cancels the anti-dipole field created by the outer coil blocks, and the fringe field is also reduced, because the magnetic moment is getting lower. However, the fringe field is still high in the vicinity of the coils and cannot be reduced by means of an iron screen, which even has the deleterious effect of enhancing it by providing a parallel flux path. These additional "anti-dipole" coils can be wound with a lower critical current density cable.

The magnet assembly becomes complex, as the iron is split into a number of solid blocks, and the coil end design is still a challenging problem due to the different coil lengths. Finally, one must point out the high stored magnetic energy due to the large high field region, and that the peak-to-bore-field ratio is not as low as in other designs. However, the Lorentz forces are smaller. The field quality is not completely optimized as it cannot be done automatically, due to the novel geometry. The 
TABLE V

COMPARISON OF $88 \mathrm{~mm}$ APERTURE GRADED DESIGNS

\begin{tabular}{|c|c|c|c|c|}
\hline Magnet type & $\begin{array}{l}\text { Slotted } \\
\cos -\theta\end{array}$ & $\begin{array}{l}\text { Layer } \\
\cos -\theta\end{array}$ & $\begin{array}{c}\text { Comm. } \\
\text { coil }\end{array}$ & Units \\
\hline Area of bare conductors/apert. & 7091 & 9156 & 10021 & $\mathrm{~mm}^{2}$ \\
\hline Area of insulated cond./apert. & 8552 & 10959 & 12078 & $\mathrm{~mm}^{2}$ \\
\hline Number of strands per aper. & 5016 & 5688 & 7088 & \\
\hline Outer iron yoke radius & 450 & 475 & 500 & $\mathrm{~mm}$ \\
\hline Current & 28000 & 25500 & 26900 & A \\
\hline Margin on load line & 10.29 & 10.09 & 9.74 & $\%$ \\
\hline Bore field & 12.71 & 13.16 & 12.65 & $\mathrm{~T}$ \\
\hline Peak field & 13.31 & 13.58 & 13.51 & $\mathrm{~T}$ \\
\hline Peak field /bore field & 1.047 & 1.032 & 1.068 & \\
\hline $\begin{array}{l}\text { Peak field for } 0 \% \text { on load line } \\
\text { Magnetic field quality }\end{array}$ & 14.84 & 15.10 & 14.97 & $\mathrm{~T}$ \\
\hline$b_{3}$ & -0.660 & 0.112 & -0.301 & $10^{-4} \mathrm{u}$. \\
\hline$b_{5}$ & -0.030 & 0.041 & -1.082 & $10^{-4} \mathrm{u}$ \\
\hline$b_{7}$ & -0.002 & -0.066 & 9.139 & $10^{-4} \mathrm{u}$. \\
\hline$b_{9}--a_{2}($ common coil $)$ & -6.624 & 1.542 & 0.149 & $10^{-4} \mathrm{u}$. \\
\hline$b_{11}-a_{4}($ common coil $)$ & -0.489 & 2.772 & 3.464 & $10^{-4} \mathrm{u}$ \\
\hline Engineering current density HF & 412 & 361 & 396 & $\mathrm{~A} / \mathrm{mm}^{2}$ \\
\hline Engineering current density LF & 629 & 551 & 604 & $\mathrm{~A} / \mathrm{mm}^{2}$ \\
\hline Self inductance /aperture & 3.219 & 4.495 & 5.209 & $\mathrm{mH} / \mathrm{m}$ \\
\hline Stored energy /aperture & 1.262 & 1.461 & 1.885 & $\mathrm{MJ} / \mathrm{m}$ \\
\hline \multicolumn{5}{|l|}{ Stray magnetic field } \\
\hline - at $50 \mathrm{~mm}$ of the iron & 0.023 & 0.019 & 0.801 & $\mathrm{~T}$ \\
\hline $\begin{array}{l}\text { - at } 1 \mathrm{~m} \text { away from the center } \\
\text { Lorentz forces }\end{array}$ & 0.004 & 0.004 & 0.067 & $\mathrm{~T}$ \\
\hline - Fx per side of aperture & 11.8 & 13.3 & 13.2 & $\mathrm{MN} / \mathrm{m}$ \\
\hline - Fy per quadrant & -2.8 & -3.3 & -0.2 & $\mathrm{MN} / \mathrm{m}$ \\
\hline $\begin{array}{l}\text { - Max. accum. stress perp. to } \\
\text { the broad side of the cable }\end{array}$ & 88 & 203 & 74 & $\mathrm{MPa}$ \\
\hline $\begin{array}{l}\text { - Max. accum. stress } \\
\text { par. to the broad side of cable }\end{array}$ & 123 & 96 & 112 & $\mathrm{MPa}$ \\
\hline
\end{tabular}

cross section of the slotted motor-type dipole is the result of eliminating the outermost coil blocks.

\section{2-D MAGNetic CAlCUlations fOR GRAdEd Designs}

Some of the selected configurations allow the use of different size or "graded" cables, as some of the coil blocks see a lower magnetic field and, therefore, the current density can be increased in the superconductor while keeping a low working point on the load line. The superconductor saving can reach up to $25 \%$ for a given bore field. Another possibility is to use a cable with the same size, but a lower critical current density. Table $\mathrm{V}$ shows the main features of the layered $\cos -\theta$, the slotted $\cos -\theta$ (see Fig. 3) and the common coil designs. The layered $\cos -\theta$ design has an elliptical iron yoke, while the slotted $\cos -\theta$ one is round. All designs rely on two cable types: a large one with 40 strands, and a smaller one with 26 .

\section{CONCLUSIONS}

A number of alternative dipole magnet designs for very high fields and large apertures have been studied by the Working Group on Magnet Design and Optimization, within the NED framework. Common starting parameters and figures of merit

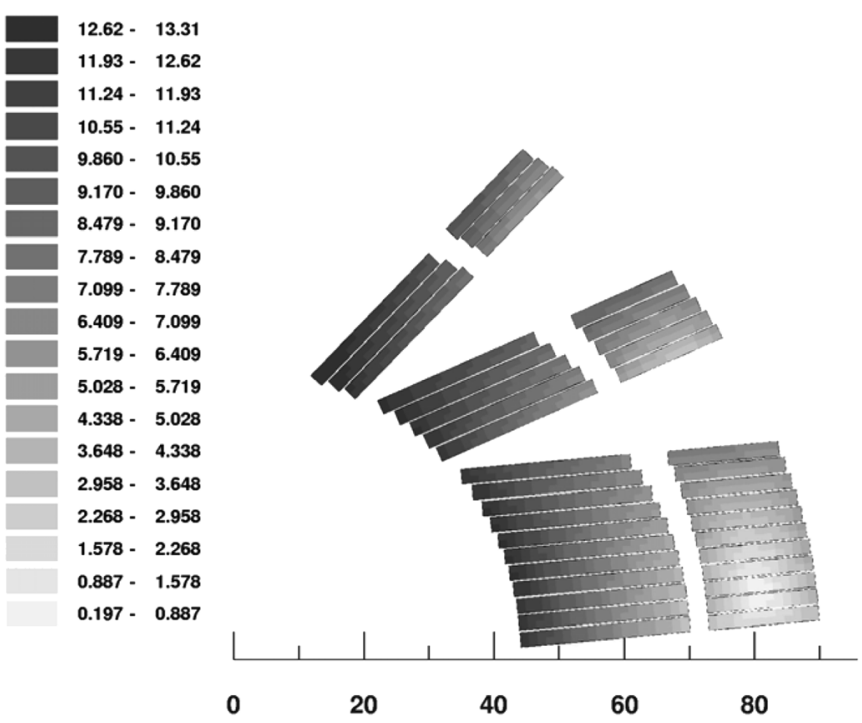

Fig. 3. Graded slotted $\cos -\theta$ magnet.

for a fair comparison have been identified. This paper summarizes the 2-D magnetic field calculations. For the $88 \mathrm{~mm}$ aperture, the conventional layered $\cos -\theta$ design is still the best one. However, for large apertures $(130 \div 160 \mathrm{~mm})$, the coil mid-plane stresses become too high for this topology. The most promising configuration for large apertures is the slotted $\cos -\theta$ design, as the others are less efficient and have obvious fabrication issues. The next step of the analysis, that is, the 2-D mechanical calculation, becomes very crucial, since the Lorentz forces are huge in all cases. A first estimate of the stresses has been done by averaging the forces on the broad cable face, but numerical computations are necessary to determine the actual local pressure, and the feasibility of the clamping structure. Finally, graded designs have been also studied whenever possible, as they allow a superconductor saving by the use of a low critical current density cable in the low field areas of the coil.

\section{REFERENCES}

[1] A. Devred et al., "Status of the Next European Dipole (NED) activity of the coordinated accelerator research in Europe (CARE) project," $\mathrm{Su}$ perconductor Science and Tech., vol. 19, pp. 67-83, March 2006.

[2] R. M. Scanlan, D. R. Dietderich, and H. C. Higley, "Development of cabling techniques for Nb3Sn and Bi-2212 wires," in Proc. Workshop on Accelerator Magnet Superconductors, Archamps, France, March 2004.

[3] N. Schwerg et al., 2D Magnetic Design and Optimization of a $88 \mathrm{~mm}$ Aperture 15 T Dipole for NED to appear in this Proceedings.

[4] D. Leroy and O. aaaVincent-Viry, Preliminary Magnetic Designs for Large-Bore and High-Field Dipole Magnets Geneva, CERN Report CERN/AT/2004-22, 2004.

[5] H. Félice, P. Védrine, and A. Mailfert, "Magnetic and Mechanical Design of a $130 \mathrm{~mm}$ Aperture $\mathrm{Nb}_{3} \mathrm{Sn}$ Dipole Magnet," to appear in this Proceedings.

[6] A. Patoux, J. Perot, and J. M. Rifflet, "Test of new accelerator superconducting dipoles suitable for high precision field," IEEE Trans. on Nuclear Science, vol. NS-30, no. 4, August 1983.

[7] F. Toral, "Progress in comparison of different high field magnet designs for NED," in Proc. Workshop on Magnet Design and Optimization, CE7RN, April 2006. 